\title{
Perinatal Cocaine Exposure Stimulates the Expression and Activation of CREB in the Neonatal Rat Heart
}

\author{
LENA S. SUN AND AARON QUAMINA \\ Departments of Anesthesiology [L.S.S., A.Q.] and Pediatrics [L.S.S.], College of Physicians and Surgeons, \\ Columbia University, New York, New York 10032, U.S.A.
}

\begin{abstract}
ABST
cAMP response binding protein (CREB) is a transcriptional
factor known to regulate gene expression. Phosphorylation of
CREB at serine 133 is necessary for CREB activation, and
quantification of phospho-CREB (p-CREB) expression is an
index of CREB activation. Because CREB expression and acti-
vation in specific brain regions are modified after chronic cocaine
administration, we sought to determine whether chronic perinatal
cocaine exposure affects the expression of CREB and p-CREB in
the postnatal rat heart. Pregnant rats were treated daily with
saline (control) or cocaine at 20 mg/kg (C20) or 60 mg/kg (C60)
by intragastric administration throughout gestation. The expres-
sion of total CREB and p-CREB was quantified in nuclear
extracts isolated from 1- and 7 -d-old neonatal rat hearts. Cardiac
nuclear p-CREB was increased in the C20 and C60 groups on d
1 and 7 of age compared with their respective age-matched
control groups. The increase in p-CREB expression corre-
sponded to an increase in cAMP response element binding
\end{abstract}
The transcription factor CREB is found ubiquitously in neuronal and other tissues and mediates the regulation of gene expression $(1,2)$. This $43-\mathrm{kD}$ protein interacts with a conserved CRE, which consists of an 8-bp palindromic sequence (TGACTCA), found in the promoter regions of many genes (3). Binding of CREB to the CRE region occurs after CREB activation by protein phosphorylation at the serine 133 site (4). CREB phosphorylation is mediated by cAMP-dependent PKA and other kinases. On exposure to high concentrations of cAMP, PKA dissociates into its catalytic and regulatory subunits and the catalytic subunit translocates to the nucleus. Nuclear PKA phosphorylates CREB at the serine 133 site to activate CREB and results in regulation of gene expression (2, $5,6)$.

Received October 1, 2001; accepted June 18, 2002.

Correspondence: Lena S. Sun, M.D., College of Physicians and Surgeons of Columbia University, Department of Anesthesiology, 630 West 168th Street-BH4-440 North, New

York, NY 10032, U.S.A.; e-mail: 1ss4@columbia.edu

Study supported by NIDA R01-DA12962.

DOI: 10.1203/01.PDR.0000049511.84836.26 activity. We also assayed nuclear protein kinase A activity, which was up-regulated in $\mathrm{d} 1$ animals with prenatal cocaine exposure, but was comparable in all groups at $\mathrm{d} 7$. Our results suggest that perinatal cocaine exposure stimulates CREB activation in the neonatal heart, and it may be mediated by different mechanisms at $\mathrm{d} 1$ and $\mathrm{d}$ 7. The changes in myocardial CREB activation induced by perinatal cocaine exposure are likely to result in modified gene expression in the neonatal heart that may account for the cardiac dysfunction reported in human neonates born to cocaine-abusing mothers. (Pediatr Res 53: 500-506, 2003)
CRE, cAMP response element
CREB, cAMP response element binding protein
PKA, protein kinase A
$\boldsymbol{\beta A R}, \beta$-adrenoreceptor

CREB is expressed and activated in the mammalian heart (7-10). Although the downstream effects of CREB activation in the heart have not been defined, its important role in cardiac function can be inferred by the severe cardiomyopathy evident in transgenic mice expressing a dominant negative form of CREB (11). In addition, in the rat heart, a down-regulation of the mRNA encoding CREB has been shown after chronic $\beta A R$ agonist stimulation (12). CRE are found in the promoter regions of the $\beta_{1}$ and $\beta_{2}$ adrenoreceptors $(13,14)$. In chronic heart failure, sustained $\beta \mathrm{AR}$ agonist stimulation from elevated circulating catecholamines is believed to be one of the mechanisms for myocardial $\beta_{1}$ and $\beta_{2}$ adrenoceptor downregulation and reduced $\beta A R$ function. Whether changes in CREB expression or activation may also play a role in $\beta A R$ down-regulation has not been investigated. The expression of total CREB in ventricular nuclear protein from failing and nonfailing human hearts was reported to be comparable (10). However, specific changes in the amount of phosphorylated or activated CREB in the failing heart were not examined.

We have previously demonstrated that the expression of a number of proteins is modified after perinatal cocaine exposure 
in the heart (15). Specifically, prenatal cocaine exposure induces an increase in myocardial $\beta$ AR density and $\mathrm{G}_{\mathrm{i} \alpha}$ protein at postnatal $\mathrm{d} 1$. It is not surprising that perinatal cocaine exposure could modify protein expression and function in the heart because children with such exposure may be considered a population at high risk for cardiovascular complications during the neonatal period and early infancy. Offspring born to mothers with a history of cocaine abuse have a high incidence of congenital anatomic cardiac and noncardiac malformations. They also show evidence of functional cardiovascular abnormalities, which include an altered pattern of heart rate variability (16), transient myocardial ischemia reduced cardiac output (17), and ventricular dysrhythmias (18). Intracellular cAMP levels are modified by $\beta A R$ and $\mathrm{G}_{\mathrm{i} \alpha}$ protein, and in turn cAMP can also influence the expression of both $\beta A R$ and $\mathrm{G}_{\mathrm{i} \alpha}$ proteins in a number of in vivo and in vitro models (19). Therefore, we sought to determine whether one possible mechanism for the changes in expression of these proteins after perinatal exposure might be related to modified expression or activation of CREB. Changes in CREB expression and protein products of immediate early genes are well documented in various brain regions after chronic opiate and cocaine administration (20). Indeed, enhanced activation of CREB has been implicated as a mechanism for drug sensitization and addiction $(1,21)$. The purpose of the present study was to investigate the possible effects of perinatal cocaine exposure on CREB expression and activation in the heart during the immediate postnatal period.

\section{METHODS}

Materials. Antibodies for Western blot analysis were obtained from New England Biolabs (Beverly, MA, U.S.A.). Oligonucleotides used for mobility shift assays were ordered from Operon Technologies (Alameda, CA, U.S.A.). Oligonucleotide CRE consensus motif was based on that of the somatostatin upstream promoter region (SOM) and has the following sequence: 5' GAT CGC CTC CTT GGC TGA CGT CAG AGA GCT AG 3'. Mutant somatostatin sequence (mSOM) is as follows: 5' GAT CGC CTC CTT GGC TCA GCA CAG AGA GCT AG 3'. Anti-CREB antibodies used in supershift analyses were purchased from Santa Cruz Biotechnologies (24H4B; Santa Cruz, CA, U.S.A.).

Animal model. Studies were approved by the Institutional Animal Care and Use Committee at the College of Physicians and Surgeons of Columbia University. Timed-pregnant (gestational day 0-1) female Sprague-Dawley rats, 90-110 d of age, were purchased and housed individually in a temperatureand humidity-controlled room on a 12/12 h light/dark cycle with ad libitum access to Purina laboratory rodent chow and drinking water. On arrival in our animal care facility, these rats were weighed, then transferred to a maternal cage within the first $24 \mathrm{~h}$. Weights were obtained on d 7, 14, and 21 of gestation.

Saline (control) or cocaine at $20 \mathrm{mg} / \mathrm{kg}$ (C20) or $60 \mathrm{mg} / \mathrm{kg}$ (C60) in equal volume was given once a day beginning on gestational d 2 until birth by intragastric administration. These doses and the intragastric route of administration have been documented to simulate the plasma and tissue concentrations achieved in the human abusers. Although we did not specifically measure plasma and tissue concentrations of cocaine and its metabolites in the animals in the present study, other investigators have documented that they simulate the concentrations achieved in human abusers. Peak plasma cocaine after intragastric administration can be as high as more than 5,000 $\mathrm{ng} / \mathrm{mL}$, which is similar to what has been reported in some human cocaine abusers $(22,23)$. Moreover, these doses have been shown to cause minimal changes in maternal weight gain and fetal wastage (24). After parturition, postpartum cocainetreated mothers continued to receive cocaine as before until postpartum $\mathrm{d}$ 7. Neonatal animals remained with their biologic mothers and were nursed by them. Animals were killed on $\mathrm{d} 1$ (D1) or d 7 (D7) of postnatal life. Animals used for the experiments at $\mathrm{d} 1$ and $\mathrm{d} 7$ were obtained from a minimum of four litters for the immunoblotting experiment and the gel shift mobility assays. Tissues from animals were harvested from different litters for each individual experiment.

Isolation of nuclear fractions. Preparations of nuclear fractions from neonatal whole hearts were performed at $4{ }^{\circ} \mathrm{C}$. Samples were always kept on ice. Hearts were first washed in ice-cold hypotonic buffer A (10 mM HEPES, $1.5 \mathrm{mM} \mathrm{MgCl}_{2}$, $10 \mathrm{mM} \mathrm{KCl}, 1 \% \beta$-mercaptoethanol, $20 \%$ glycerol, $5 \mathrm{mM}$ $\mathrm{Na}_{3} \mathrm{VO}_{4}$, and protease inhibitor cocktail from Roche Applied Science, Indianapolis, IN, U.S.A.). Hearts were then disrupted in $0.5 \mathrm{~mL}$ of buffer A using a Dounce homogenizer. After 5-10 strokes in the Dounce homogenizer, samples were further homogenized by three short bursts, $3-5 \mathrm{~s}$ each, with a Polytron tissue homogenizer. Whole heart homogenates were then centrifuged for $5 \mathrm{~min}$ at $10,000 \times g$. Pellets were briefly washed with buffer A then resuspended in buffer B (20 mM HEPES, $1.5 \mathrm{mM} \mathrm{MgCl} 2,0.5 \mathrm{mM}$ EDTA, $0.5 \mathrm{M} \mathrm{NaCl}, 0.1 \%$ Triton $\mathrm{X}-100,1 \% \beta$ mercaptoethanol, $25 \%$ glycerol, $5 \mathrm{mM} \mathrm{Na}_{3} \mathrm{VO}_{4}$, and protease inhibitor cocktail), and incubated in buffer B for $1 \mathrm{~h}$ with occasional mixing (4). After $1 \mathrm{~h}$, the protein suspension was centrifuged for $10 \mathrm{~min}$ at $16,000 \times \mathrm{g}$. The supernatant containing nuclear proteins was then aliquoted and immediately frozen and stored at $-80^{\circ} \mathrm{C}$. Isolation of nuclear fraction was confirmed by immunoblotting using an antibody specific for H-1 histone, a nuclear-specific protein (Fig. 1).

Electrophoretic mobility shift assay. Electrophoretic mobility shift assay was carried out by mixing $10 \mu \mathrm{g}$ of nuclear fraction proteins, 2 pmol of CRE-promoter containing oligonucleotide 5 ' end-labeled with ${ }^{32} \mathrm{P}, 10 \mathrm{mM}$ Tris $\mathrm{pH} 7.5,100$ $\mathrm{mM} \mathrm{NaCl}, 4 \%$ glycerol, $5 \mathrm{mM}$ dithiothreitol, $100 \mu \mathrm{g} / \mathrm{mL}$ BSA, and $100 \mu \mathrm{g} / \mathrm{mL}$ poly dI-dC. Assays were incubated at $25^{\circ} \mathrm{C}$ for 20 min. For supershift analysis $2 \mu \mathrm{L}$ of antibody (24H4B) was added directly to the reaction mixture and incubated at $25^{\circ} \mathrm{C}$

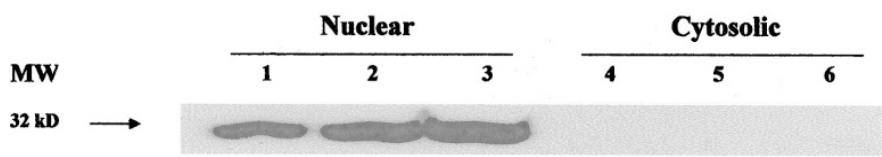

Figure 1. The gel demonstrates that in three different preparations, the expression of nuclear-specific protein histone 1 [molecular weight (MW) 32 $\mathrm{kD}$ ] was exclusively in the isolated nuclear fractions (lanes 1, 2, and 3) and was absent in the cytosolic fractions (lanes 4, 5, and 6). 
for $20 \mathrm{~min}$. Samples were then resolved on a native $3.5 \%$ polyacrylamide gel in $1 \times$ TGE $(100 \mathrm{mM}$ Tris, $760 \mathrm{mM}$ glycine, $1 \mathrm{mM}$ EDTA). Typically, gels were run for approximately $1.5 \mathrm{~h}$ at $30 \mathrm{~mA}$.

Western blot. For Western blot analyses, $40 \mu \mathrm{g}$ of nuclear fraction proteins were loaded onto Novex SDS-PAGE 4 to $20 \%$ precasted gels. Proteins were resolved and transferred to PVDF membrane (Bio-Rad, Hercules, CA, U.S.A.). Membranes were briefly washed in PBS-1\% Tween, then blocked for $1 \mathrm{~h}$ in $5 \%$ low-fat milk. Membranes were then incubated overnight at $4{ }^{\circ} \mathrm{C}$ with either anti-CREB or anti-phospho-CREB diluted 1:1000 in PBS-1\%Tween containing 1\% BSA. Membranes were then washed three times in PBS-1\% Tween for 5-10 min each, after which they were incubated with secondary antibody diluted 1:3000 for $1 \mathrm{~h}$. Membranes were again washed three times, 5-10 min each. Signal was developed using Amersham ECL Reagent according to manufacturer's specifications (Amersham Pharmacia Biotech, Piscataway, NJ, U.S.A.).

PKA activity assay. A colorimetric PKA assay kit (Pierce Biochemical, Rockford, IL, U.S.A.) was used to determine PKA activity. A standard curve was constructed with the range of $0.03-1.0 \mathrm{U}$ of PKA activity. For each sample, $5 \mu \mathrm{g}$ of protein was used, and determinations were made in duplicate. All sample assay activities were within the range of the standard curve.

Immunoprecipitation. All reagents for these reactions were maintained at $4^{\circ} \mathrm{Ctwo}$ hundred micrograms of nuclear protein was incubated with anti-CREB antibody (Santa Cruz Technology) and immunoprecipitation buffer (20 mM HEPES, $1 \mathrm{mM}$ EDTA, $0.2 \%$ NP-100, $100 \mu \mathrm{g} / \mathrm{mL}$ BSA, and Roche Biochemicals protease inhibitor cocktail) in a total volume of $800 \mu \mathrm{L}$. Reactions were allowed to proceed overnight at $4^{\circ} \mathrm{C}$, and were mixed with $50 \mu \mathrm{L}$ of protein $\mathrm{A} / \mathrm{G}$-agarose bead suspension on the following day for $1 \mathrm{~h}$ at $4{ }^{\circ} \mathrm{C}$. The protein $\mathrm{A} / \mathrm{G}$-agarose beads-immuno complex was spun at $10,000 \times g$ for $15 \mathrm{~s}$. Beads were then washed three times in $1 \mathrm{~mL}$ of ice-cold PBS/0.1\%Tween. After final wash, supernatant was removed, pellets were spun again, and the residual fluid was removed. Pellets were then resuspended and boiled in SDS loading buffer. Samples were then loaded onto 10\% SDS-polyacrylamide gel along with the corresponding original nuclear extract. Western blot analysis was performed to assess PKA $_{C \alpha}$ association with CREB.

Data analysis. Differences within each age across various treatment groups were analyzed by ANOVA. Differences between control and cocaine-treated groups were then analyzed by the post hoc comparison using modified Bonferroni's $t$ test. Results were deemed statistically significant if $p<0.05$.

\section{RESULTS}

Effect of prenatal cocaine exposure on CREB in cardiac nuclei in 1-d-old rats. To examine the effect of prenatal cocaine exposure on CREB expression and activation, 1-d-old neonatal rat hearts were used to obtain isolated nuclear preparations after gestational cocaine exposure at two different doses of cocaine as described in "Methods." The low dose of prenatal cocaine exposure at $20 \mathrm{mg} / \mathrm{kg}(\mathrm{C} 20)$ did not change the total amount of nuclear CREB, but the high dose of cocaine at $60 \mathrm{mg} / \mathrm{kg}$ (C60) induced a significant increase in total CREB when compared with controls that were only exposed to saline (CTL; Fig. 2A). We quantified the amount of immunodetectable phospho-CREB to assess CREB activation. Prenatal cocaine exposure at both doses significantly increased cardiac phospho-CREB expression compared with controls (Fig. 2B). A representative immunoblot is shown above the summary graph for CREB (Fig. 2A) and phospho-CREB (Fig. 2B). The increase in phospho-CREB expression corresponded to an enhanced nuclear protein binding activity to the labeled ${ }^{32} \mathrm{P}$ somatostatin CRE promoter (5' GATCGCCTCCTTGGCTGACGTCAGAGAGCTAG 3'; Fig. 3A). The specificity of CRE binding by the nuclear extract was confirmed using a labeled mutant ${ }^{32} \mathrm{P}$ somatostatin CRE promoter (5' GATCGCCTCCTTGGCTCAGCACAGAGAGCT 3'; data not shown). A representative gel shift mobility assay is shown (Fig. $3 B$ ). Moreover, when a CREB-specific antibody was added to the reaction mixture, the mobility of the DNA-protein complex was further retarded (data not shown). The illustrated gel shift mobility assay is representative of four other similar experiments.

Effect of perinatal cocaine exposure on CREB in cardiac nuclei in 7-d-old rats. In 7-d-old pups, cocaine exposure was extended beyond the prenatal period for $7 \mathrm{~d}$ postnatally (perinatal exposure). The effect of this perinatal exposure was determined using cardiac nuclei from 7-d-old rats. Perinatal cocaine exposure did not alter myocardial nuclear CREB expression in C20 or C60 compared with controls (Fig. 4A). However, perinatal cocaine exposure did significantly increase CREB activation inasmuch as immunodetectable phosphoCREB was significantly greater in cocaine-exposed groups (C20 and C60) than in the control group (CTL; Fig. 4B). A representative immunoblot is shown above the summary graph for CREB (Fig. 4A) and phospho-CREB (Fig. 4B). Perinatal
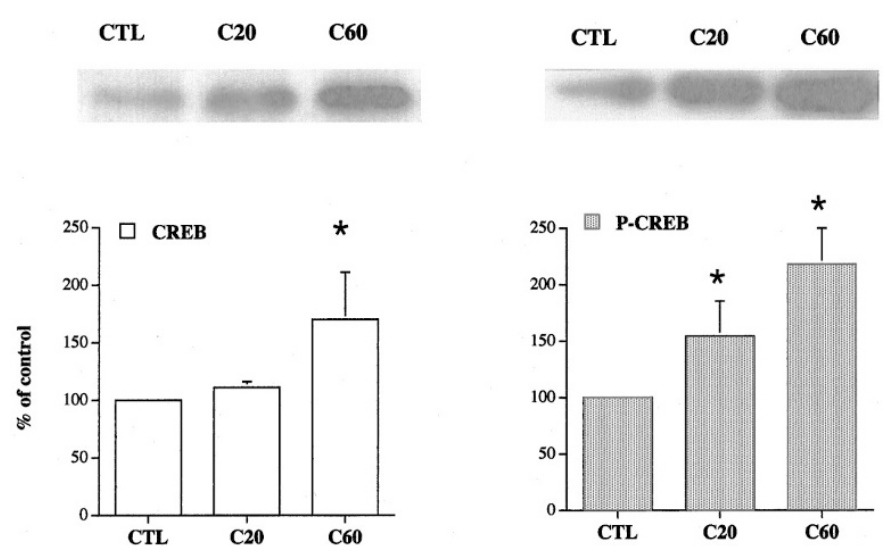

Figure 2. $A$, total nuclear CREB expression at d 1 of age was similar after chronic daily prenatal saline $(C T L)$ or cocaine exposure at $20 \mathrm{mg} / \mathrm{kg}(C 20)$. After prenatal cocaine exposure at $60 \mathrm{mg} / \mathrm{kg}$ daily $(\mathrm{C60})$, total nuclear CREB was significantly increased compared with CTL (all $n=10$ ). $B$, immunodetectable cardiac nuclear phospho-CREB $(P-C R E B)$ was significantly greater in both C20 and C60 groups compared with CTL. The amount of total and phospho-CREB are expressed as \% CTL (all $n=10$ ). Upper panel, representative gels for total and phospho-CREB are shown. ${ }^{*} p<0.05$ versus CTL. 
A

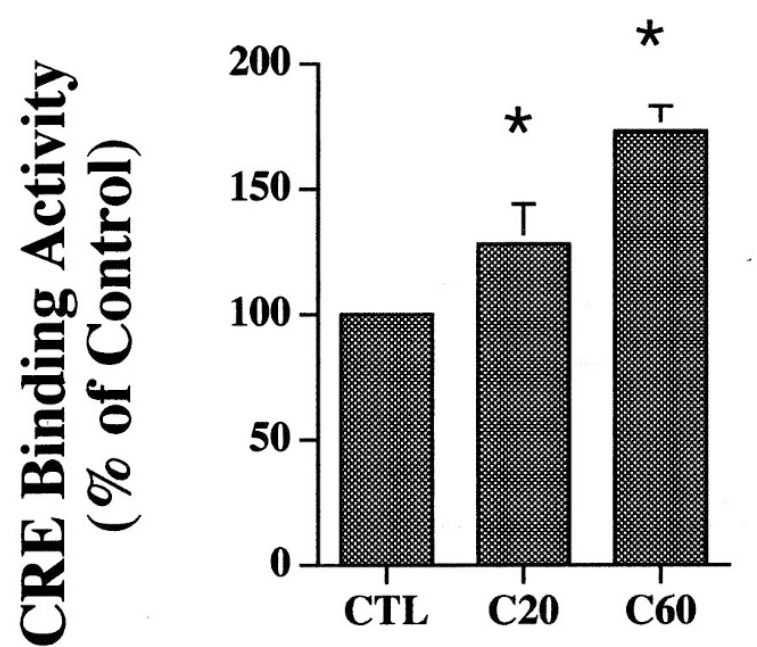

B

\section{Protein-CRE Complex}

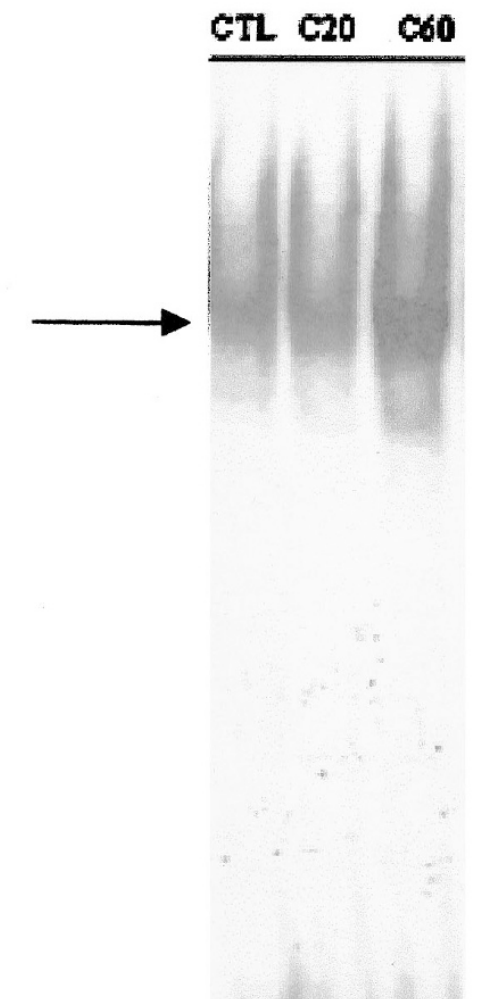

\section{Unbound ${ }^{32} \mathbf{P}$ end labeled CRE}

Figure 3. A, electrophoretic mobility shift analysis of CRE binding activities in 1-d-old neonatal rat cardiac nuclear extracts from CTL (daily intrauterine saline treatment), C20 (daily maternal treatment with cocaine at $20 \mathrm{mg} / \mathrm{kg}$ during gestation), and C60 (daily maternal treatment with cocaine at $60 \mathrm{mg} / \mathrm{kg}$ during gestation). The assays were performed with radiolabeled probes containing intact somatostatin promoter (SOM_. CRE binding activities were increased in cocaine-exposed groups compared with CTL using SOM-CRE probes. Addition of an antibody directed at CREB caused a supershift of the DNA-protein complex ( $n=5$ for each treatment group). ${ }^{*} p<0.05 . B$, representative gel is shown.

cocaine exposure also significantly enhanced nuclear protein CRE binding activity, and a supershift of the DNA-protein complex was also observed (Fig. $5 A$ ). Figure $5 B$ is representative of five similar experiments illustrating cardiac nuclear CRE binding was increased in $\mathrm{d} 7 \mathrm{C} 20$ and $\mathrm{C} 60$ groups compared with controls, and that the mobility of the DNA-protein complex was further retarded (supershifted) when a CREB-specific antibody was added to the reaction mixture.

PKA activity in cardiac nuclei from 1-d-old and 7-d-old rats. To examine whether PKA activity may be one of the mechanisms for the cocaine-induced increase in CREB phosphorylation, we assayed PKA activity in the cardiac cytosolic and nuclear fractions isolated from the different treatment groups at d 1 and d 7 of age. Cytosolic PKA activity was minimally detectable (data not shown), and the majority of PKA activity was found in the nuclear fraction at both ages. An age-related increase in cardiac nuclear PKA activity was observed, with d 7 cardiac nuclear PKA activity being significantly greater than 1 cardiac nuclear PKA activity. In addition, we found that nuclear PKA activity was significantly higher in $\mathrm{d} 1 \mathrm{C} 20$ and $\mathrm{C} 60$ groups $(25 \pm 7 \%$ and $16 \pm 2 \%$ above control, $p<0.05$ for both) compared with controls (Fig. $6 A$ ). Moreover, the amount of immunodetectable catalytic subunit of PKA was higher in C20 and C60 nuclear extracts than in controls (data not shown). In contrast, PKA activity (15 \pm 9 and $3 \pm 3 \%$ above control, respectively for $\mathrm{C} 20$ and $\mathrm{C} 60$, $p>0.05$ for both; Fig. $6 B$ ) and the amount of immunodetectable PKA catalytic subunit (data not shown) were comparable among all groups at $\mathrm{d} 7$. We quantified the immunodetectable catalytic $\alpha$ subunit of PKA after immunoprecipitation with a CREB-specific antibody and found it to be increased in cocaine-exposed hearts at $\mathrm{d} 1$, but similar in all groups at $\mathrm{d} 7$ (data not shown). 

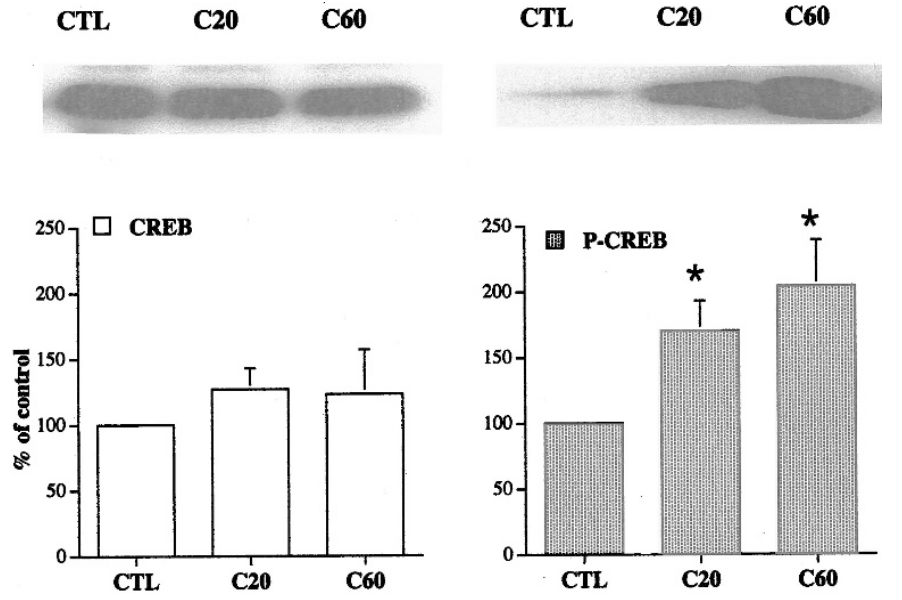

Figure 4. $A$, expression of total cardiac nuclear CREB protein was comparable in all groups on $\mathrm{d} 7$ (all $n=10)$. $B$, the amount of phospho-CREB $(P-C R E B)$ was significantly up-regulated after perinatal cocaine exposure at both $20 \mathrm{mg} / \mathrm{kg}(C 20)$ and $60 \mathrm{mg} / \mathrm{kg}$ (C60; all $n=10)$. Upper panel, representative experiments for CREB and phospho-CREB are shown. ${ }^{*} p<$ 0.05 versus CTL.

\section{DISCUSSION}

We found that immunodetectable CREB and phosphoCREB were expressed in the neonatal rat heart at $1 \mathrm{~d}$ of life, and were increased after intrauterine cocaine exposure. Therefore, CREB was expressed and activated in the postnatal heart, and both CREB and phospho-CREB were modulated by gestational exposure to cocaine. The increase in CREB activation was sustained at $\mathrm{d} 7$ of age, although no actual increase in total CREB was observed. The enhanced CREB activation corresponded to an increase in CRE binding activity at both $\mathrm{d} 1$ and d 7. The increase in CREB activation appeared to be effected by an increase in the amount of available CREB as well as an augmentation in CREB phosphorylation at $\mathrm{d} 1$, particularly at the higher dose of prenatal cocaine exposure. In contrast, the increase in phospho-CREB at $\mathrm{d} 7$ can probably be attributed to enhanced net phosphorylation of CREB rather than an increase in total CREB expression, because nuclear CREB did not appear to change at $1 \mathrm{wk}$ of age.

The increased expression of phospho-CREB would probably affect the expression of genes that contain CRE in their promoter regions. A number of genes that are important in the regulation of cardiac function have been shown to contain CRE in their promoter regions ( $\beta \mathrm{AR}$, for example). Expression and activation of CREB in hearts have only recently been documented $(8,14,16)$, but the role of CREB in regulating gene expression in cardiomyocytes has not been extensively investigated. From studies performed in mice expressing the dominant negative form of CREB, there is evidence, however, that CREB is important in regulating genes associated with cardiac contractile function. Transgenic mice overexpressing the dominant negative CREB were found to have severe cardiomyopathy (11). Although the specific CREB-targeted genes that were altered in cardiomyocytes from these mice have not been identified, these animals did not appear to have abnormal contractile protein expression or increased apoptosis. Prenatal cocaine exposure has been reported to cause cardiac arrhyth- mias and cardiac contractile dysfunction in the neonatal human population $(16,17,25)$. Our observation that CREB activation was up-regulated suggests that prenatal cocaine exposure could lead to qualitative and quantitative changes in gene or protein expression that affect cardiac conduction and contractile function. The present study was undertaken, in part, to examine whether changes in CREB expression or activity might be the basis for the up-regulation in $\beta$ AR density and immunodetectable $G_{i}$ we had reported earlier. Our finding that CREB was increased at both $\mathrm{d} 1$ and $\mathrm{d} 7$, while $\beta \mathrm{AR}$ and $\mathrm{G}_{\mathrm{i} \alpha}$ up-regulation was only demonstrable at $d 1$, would argue against a CREmediated increase in gene expression as the mechanism for the increase in $\beta A R$ and $\mathrm{G}_{\mathrm{i} \alpha}$. The specific changes in gene expression in the neonatal rat heart after perinatal cocaine exposure are the subject of ongoing investigation.

Cocaine-induced effects on CREB in the CNS have been implicated as one possible molecular mechanism for addiction. Cocaine stimulates dopaminergic $\mathrm{D}_{1}$-receptor activation in regions that contain dopaminergic-rich neurons. $\mathrm{D}_{1}$ receptors may mediate CREB phosphorylation via several different signaling pathways including the cAMP-PKA pathway and increased $\mathrm{Ca}^{2+}$ influx through the L-type calcium channels or the ligand-gated $N$-methyl-D-aspartate receptors. The rewarding effects of cocaine are diminished after repeated use of the drug, and the biochemical correlates for these physiologic and behavioral findings include an up-regulation of the cAMP signaling pathway, altered CREB phosphorylation, and changes in gene expression. In a rat model in which CREB was overexpressed, the rewarding effects of cocaine were reduced, further supporting the idea that CREB regulation by cocaine may be the underlying mechanism for drug tolerance and addiction. In the heart, cocaine's actions are related to effects exerted by the sympathetic neurotransmitter norepinephrine. Norepinephrine released from sympathetic nerve terminals binds to the $G$ protein-coupled $\beta$ ARs to regulate cardiac contractile function via activation of the cAMP-PKA pathway and the L-type calcium channels. Our earlier studies (15) have found prenatal cocaine exposure altered the myocardial $\beta$ AR-cAMP signaling pathway at $d 1$ of age. We have now extended our study to examine PKA activity after prenatal cocaine exposure, and observed an increase in PKA activity at $d 1$. Therefore, norepinephrine-mediated up-regulation in cAMP-PKA signaling pathway could be one mechanism for the enhanced CREB phosphorylation. Because the up-regulation in PKA activity at d 1 was relatively modest, other signaling pathways may also be involved in mediating the phosphorylation of CREB at serine 133. Interestingly, although CREB phosphorylation remained significantly greater in the cocaine-exposed groups at $\mathrm{d}$ 7 , our results suggest that myocardial nuclear PKA did not appear to play a role in the up-regulation of CREB phosphorylation. It is likely that CREB phosphorylation secondary to continued cocaine exposure during the postnatal period involves PKA-independent mechanisms. However, because basal levels of PKA activity were much greater at d 7 compared with $d 1$, a modest cocaine-induced increase in PKA activity may be less evident at d 7. Therefore, additional studies will be needed to conclusively exclude the role of PKA in effecting changes in phospho-CREB expression at $\mathrm{d} 7$. 
A

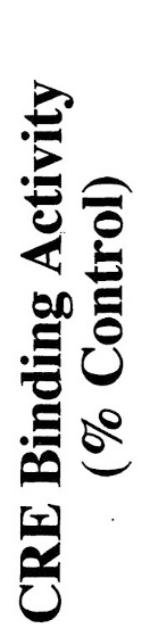

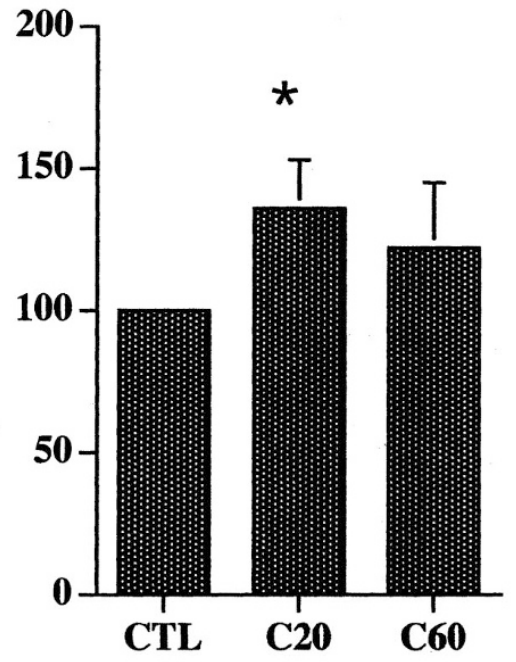

B

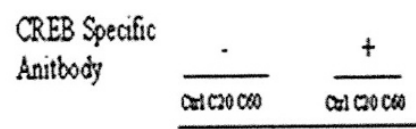

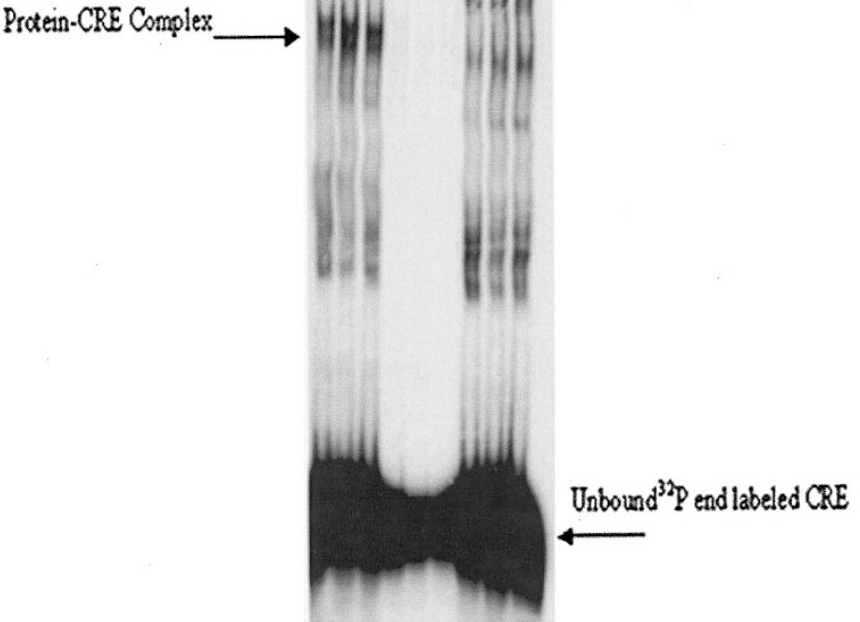

Figure 5. $A$, CRE binding activity is significantly greater in cardiac nuclear extracts from C20 and C60 compared with CTL $(n=5$ in each group). $* p<0.05$. $B$, representative electrophoretic mobility shift assay is illustrated using cardiac nuclear extracts from $\mathrm{d} 7$ animals after perinatal saline (CTL), cocaine at $20 \mathrm{mg} / \mathrm{kg}$ $(C 20)$, and cocaine at $60 \mathrm{mg} / \mathrm{kg}(\mathrm{C} 60)$ treatment, and radiolabeled SOM and mSOM CRE probes. CRE binding activities were significantly greater in C20 and C60 compared with CTL using SOM-CRE probes, and no binding activity was observed using mSOM-CRE probes (middle panel of three lanes), indicating that all binding activities were CRE-specific. Addition of an antibody directed at CREB resulted in a significant retardation of the mobility of the DNA-protein complex. The supershift indicates that most, although not all, of the binding was attributable to CREB in the DNA-protein complex. Similar results are found in four different experiments.
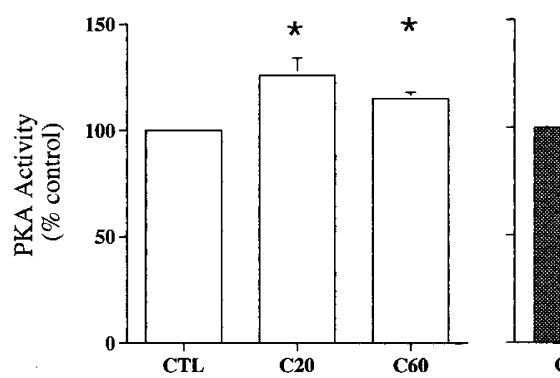

effect of cocaine exposure on some of the possible alternative signaling pathways that could mediate CREB phosphorylation. These include calcium-calmodulin II kinase and MAP kinases. In addition, cocaine may also induce changes in CREB phosphorylation via changes at the level of phosphatase enzyme activity.

\section{CONCLUSION}

In conclusion, intrauterine cocaine exposure stimulated

Figure 6. A, PKA activity was assayed in nuclear extracts from $\mathrm{d} 1$ neonatal rat hearts that had received intrauterine saline $(C T L, n=6)$, cocaine at 20 $\mathrm{mg} / \mathrm{kg}(C 20, n=6)$, and cocaine at $60 \mathrm{mg} / \mathrm{kg}(C 60, n=6)$. PKA activity was significantly higher in both groups with prenatal cocaine exposure $(\mathrm{C} 20=$ $12.98 \pm 1.3 \mathrm{U} / \mathrm{mg}$ protein and $\mathrm{C} 60=12.1 \pm 1.5 \mathrm{U} / \mathrm{mg}$ protein) compared with the control group $(\mathrm{CTL}=10.6 \pm 1.3 \mathrm{U} / \mathrm{mg}$ protein). PKA activity was expressed as $\%$ of CTL. ${ }^{*} p<0.05$ versus CTL. $B$, PKA activity in cardiac nuclei of $\mathrm{d} 7$ animals was comparable in CTL (16.8 $\pm 1.2 \mathrm{U} / \mathrm{mg}$ protein), $\mathrm{C} 20$ $(19.6 \pm 2.5 \mathrm{U} / \mathrm{mg}$ protein), and C60 (17.4 $\pm 1.3 \mathrm{U} / \mathrm{mg}$ protein) groups (all $n$ $=7)$.

Nevertheless, our results would suggest that different signal transduction pathways may be more prominently used at specific developmental ages to stimulate CREB phosphorylation. In fact, this has been documented previously in noncardiac tissues. In the rat cerebrum, CREB phosphorylation in young (11-d-old) oligodendrocytes was exclusively mediated by the cAMP-PKA signaling pathway, but CREB phosphorylation in immature oligodendrocytes (4-d-old) involved signaling pathways of protein kinase C (26). Future studies will examine the

CREB phosphorylation, and this was associated with increased PKA activity at $1 \mathrm{~d}$ of age. Perinatal cocaine exposure during the entire gestational period and thereafter until postnatal $\mathrm{d} 7$ also promoted CREB phosphorylation, which appeared not to involve changes in PKA activity. Therefore, perinatal cocaine exposure stimulated myocardial CREB activation and the mechanisms may involve different signaling pathways depending on the postnatal age.

Acknowledgments. The authors thank Dr. Michael R. Rosen and Dr. Carol Hirshman for their insightful comments on the manuscript and Erlinda Samaniego for her technical assistance.

\section{REFERENCES}

1. Carlezon WA, Thome J, Olson VG, Lane-Ladd SB, Brodkin ES, Hiroi N, Duman RS, Neve RL, Nestler EJ 1998 Regulation of cocaine reward by CREB. Science 282:2272-2275

2. Montminy M 1997 Transcriptional regulation by cyclic AMP. Annu Rev Biochem 66:807-822 
3. Andrisani OM 1999 CREB-mediated transcriptional control. Crit Rev Eukaryot Gene Expr 9:19-32

4. Shaywitz AJ, Greenberg ME 1999 CREB: a stimulus-induced transcription factor activated by a diverse array of extracellular signals. Annu Rev Biochem 68:821861

5. Meinkoth JL, Alberts AS, Went W, Fantozzi D, Taylor SS, Hagiwara M, Montminy M, Feramisco JR 1993 Signal transduction through the cAMP-dependent protein kinase. Mol Cell Biochem 127-128:179-186

6. Daniel PB, Walker WH, Habener JF 1998 Cyclic AMP signaling and gene regulation. Annu Rev Nutr 18:353-383

7. Goldspink PH, Russell B 1994 The cAMP response element binding protein is expressed and phosphorylated in cardiac myocytes. Circ Res 74:1042-1049

8. Goldspink PH, Russell B 1996 Physiological role of phosphorylation of the cyclic AMP response element binding protein in rat cardiac nuclei. Cell Tissue Res 285:379-385

9. Muller FU, Boknik P, Horst A, Knapp J, Linck B, Schmitz W, Vahlensieck U, Bohm M, Deng MC, Scheld HH 1995 cAMP response element binding protein is expressed and phosphorylated in the human heart. Circulation 92:2041-2043

10. Muller FU, Boknik P, Knapp J, Luss H, Neumann J, Vahlensieck U, Bohm M, Deng MC, Scheld HH, Schmitz W 1997 Quantification of the cAMP response element binding protein in ventricular nuclear protein from failing and nonfailing human hearts. Biochem Biophys Res Commun 236:351-354

11. Fentzke RC, Korcarz CE, Lang RM, Lin H, Leiden JM 1998 Dilated cardiomyopathy in transgenic mice expressing a dominant- negative CREB transcription factor in the heart. J Clin Invest 101:2415-2426

12. Muller FU, Boknik P, Horst A, Knapp J, Linck B, Schmitz W, Vahlensieck U, Walter A 1995 In vivo isoproterenol treatment leads to downregulation of the mRNA encoding the cAMP response element binding protein in the rat heart. Biochem Biophys Res Commun 215:1043-1049

13. Collins S, Altschmied J, Herbsman O, Caron MG, Mellon PL, Lefkowitz RJ 1990 A cAMP response element in the beta 2-adrenergic receptor gene confers transcriptional autoregulation by cAMP. J Biol Chem 265:19330-19335
14. Tseng YT, Stabila J, McGonnigal B, Nguyen TT, Padbury JF 1998 An inverted cAMP response element mediates the cAMP induction of the ovine beta 1-adrenergic receptor gene. Biochem Mol Biol Int 46:1127-1134

15. Sun LS 2000 Perinatal cocaine exposure impairs myocardial beta-adrenoceptor signaling in the neonatal rat. Anesth Analg 90:50-56

16. Mehta SK, Finkelhor RS, Anderson RL, Harcar-Sevcik RA, Wasser TE, Bahler RC 1993 Transient myocardial ischemia in infants prenatally exposed to cocaine. J Pediatr 122:945-949

17. van de Bor M, Walther FJ, Ebrahimi M 1990 Decreased cardiac output in infants of mothers who abused cocaine. Pediatrics 85:30-32

18. Geggel RL, McInerny J, Estes III NA 1989 Transient neonatal ventricular tachycardia associated with maternal cocaine use. Am J Cardiol 63:383-384

19. Bristow MR, Hershberger RE, Port JD, Gilbert EM, Sandoval A, Rasmussen R, Cates AE, Feldman AM 1990 Beta-adrenergic pathways in nonfailing and failing human ventricular myocardium. Circulation 82:I-12-I-25

20. Nestler EJ 1997 Molecular mechanisms of opiate and cocaine addiction. Curr Opin Neurobiol 7:713-719

21. Nestler EJ, Erdos JJ, Terwilliger R, Duman RS, Tallman JF 1989 Regulation of G proteins by chronic morphine in the rat locus coeruleus. Brain Res 476:230-239

22. Dow-Edwards D, Fico TA, Osman M, Gamagaris Z, Hutchings DE 1989 Comparison of oral and subcutaneous routes of cocaine administration on behavior, plasma drug concentration and toxicity in female rats. Pharmacol Biochem Behav 33:167-173

23. Dow-Edwards D 1990 Fetal and maternal cocaine levels peak rapidly following intragastric administration in the rat. J Subst Abuse 2:427-437

24. Spear LP, Frambes NA, Kirstein CL 1989 Fetal and maternal brain and plasma levels of cocaine and benzoylecgonine following chronic subcutaneous administration of cocaine during gestation in rats. Psychopharmacology 97:427-433

25. Lipshultz SE, Frassica JJ, Orav EJ 1991 Cardiovascular abnormalities in infants prenatally exposed to cocaine. J Pediatr 118:44-51

26. Sato-Bigbee C, Pal S, Chu AK 1999 Different neuroligands and signal transduction pathways stimulate CREB phosphorylation at specific developmental stages along oligodendrocyte differentiation. J Neurochem 72:139-147 